\title{
Weibull Statistics of Tensile-Shear Strength of 5083 Aluminum Alloy after Friction Stir Spot Welding
}

\author{
Chia-Wei Lin, Fei-Yi Hung*, Truan-Sheng Lui and Li-Hui Chen \\ Department of Materials Science and Engineering, National Cheng Kung University, Tainan 701, Taiwan
}

\begin{abstract}
Friction stir spot welding has been adopted to replace resistance spot welding for Al alloys. This study investigates the effects of plunge depth, rotation speed, and welding duration on the microstructural characteristics of the weld, bonding strength and reliability of $5083 \mathrm{Al}$ alloy. Bonding strength is evaluated using a tensile-shear test and the reliability is analyzed using a Weibull model. According to the experimental results, the major difference in the microstructure was the range of the stirring zone (SZ). The range of the SZ and the tensile-shear failure loading (TSFL) were enhanced when the welding duration or plunge depth was increased. The optimal rotation speed changed with plunge depth. Two fracture modes (tearing mode and cup pull-out mode) appeared for all parameter combinations. When the range of the SZ was deep and broad, the cup pull-out mode was the main fracture mechanism. The TSFL of the cup pull-out mode was higher than that of the tearing mode. Furthermore, the Weibull parameters of the cup pull-out mode were higher and the distribution curve shapes were better. Higher plunge depth, longer welding duration, and a suitable rotation speed made the fracture mode of the tensile-shear test be the cup pull-out mode and led to high bonding strength and good reliability. [doi:10.2320/matertrans.M2014281]
\end{abstract}

(Received July 31, 2014; Accepted October 27, 2014; Published December 25, 2014)

Keywords: aluminum alloy, friction stir spot welding (FSSW), Weibull analysis

\section{Introduction}

Because of their high tensile strength and good formability, $5 \mathrm{xxx}$ series aluminum alloys such as 5052 and 5083 alloys are applied extensively in the land transportation industry for reducing vehicle weight and energy consumption. ${ }^{1)}$ Resistance spot welding (RSW) is the primary method used for joining automotive structural components. ${ }^{2)}$ A vehicle's structural performance depends on the welded joint structural properties. However, traditional RSW is not suitable for joining aluminum alloys ${ }^{3)}$ due to its high electrical current requirements and inconsistent quality of the spot welds.

Friction stir spot welding ${ }^{4-6}$ (FSSW), a derivative of friction stir welding (FSW), is an efficient method for refining microstructure that produces a specific welding region, called the stirring zone (SZ), with fine and equiaxed grains due to dynamic recrystallization. ${ }^{7-12)} \mathrm{FSSW}$ is the preferred method for joining aluminum structural components, and is currently used for applications such as land transportation vehicles, airplanes, and ships. Three factors affect the quality of FSSW joints, ${ }^{3,13-15)}$ namely penetration depth of the tool pin, the rotation speed of the tool, and welding duration. According to previous reports, ${ }^{13-15)}$ FSSW joint defects affect the fatigue life of FSSW joints. Based on previous studies, ${ }^{16-21)}$ the tensile failure strength of FSSW joints has a relatively wide distribution and the joints have lower reliability. Weibull model $^{22,23)}$ can be used to evaluate the failure probability of FSSW joints, which is closely related to the structural defects. Nevertheless, FSSW isn't fused and don't have resolidification that can minimize the inevitable defects.

Consequently, the variability of joint strength is correlated with the quality of the FSSW joint. The microstructure of FSSW-joined zones and the fraction of the effective area during FSSW affect joint strength. The effects of rotation speed and friction stirring duration $(<10 \mathrm{~s})$ on FSSW joint reliability are here examined using a statistical investigation.

*Corresponding author, E-mail: fyhung@mail.ncku.edu.tw
Table 1 Chemical composition of 5083 Al alloy.

\begin{tabular}{cccccc}
\hline Element & $\mathrm{Mg}$ & $\mathrm{Mn}$ & $\mathrm{Fe}$ & $\mathrm{Si}$ & $\mathrm{Al}$ \\
\hline mass\% & 4.58 & 0.56 & 0.27 & 0.12 & $\mathrm{Bal}$. \\
\hline
\end{tabular}

The aim of the present study is to evaluate the formation mechanism and fracture characteristic load of FSSW-joined 5083 alloy under a short friction stirring time and to evaluate joint reliability using Weibull statistics.

\section{Materials and Experimental Methods}

2-mm-thick 5083-O aluminum alloy rolled sheets with the chemical composition shown in Table 1 was used. The Al alloy sheets were machined into FSSW specimens with dimensions of $75 \mathrm{~mm}$ (length) $\times 30 \mathrm{~mm}$ (width). As shown in Fig. 1(a), during the FSSW process, a cylindrical rotating tool with a protruding pin plunged into two overlapping 5083-O sheets. Figure 1(b) shows the tool size. Two specimens were bonded via heat and severe plastic deformation. A cup-shaped stirring zone was generated by dynamic recrystallization. In this study, the downward push force was controlled to be about $3.0 \mathrm{kN}$. Plunge depth of 2.5 and $3.5 \mathrm{~mm}$ were used. The specimens did not bond with an insufficient plunge depth and were penetrated or broke with an excessive plunge depth. The welding duration was from 4 to $10 \mathrm{~s}$. The rotation speed was from 2000 to $3500 \mathrm{rpm}$, a range determined from a pre-experiment. The specimens were coded as follows: FSSW $X / Y-Z$, where $X$ is the plunge depth (in $\mathrm{mm}$ ), $Y$ is the rotation speed (in $\mathrm{rpm}$ ), and $Z$ is the welding time (in s). For example, FSSW2.5/2500-10 is a specimen obtained with a $2.5-\mathrm{mm}$ plunge depth, a 2500 -rpm rotation speed, and a 10 -s welding time.

After welding, the lap-joined specimens were crosssectioned parallel to the welding direction for metallographic examination. The cross section of the metallographic speci- 


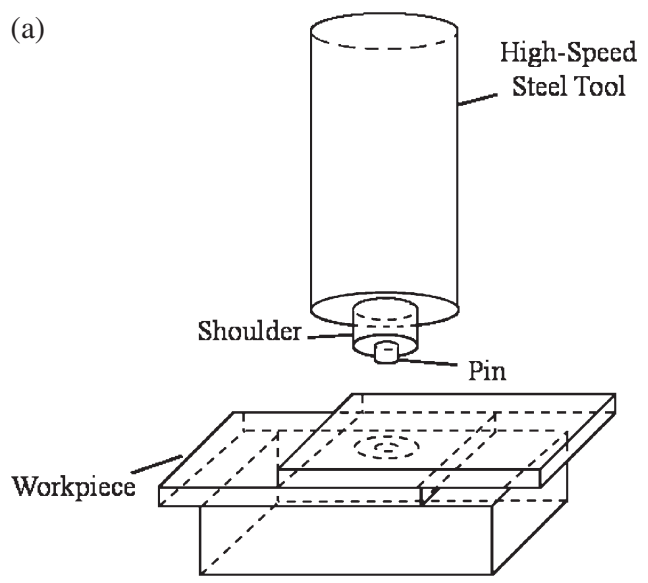

(b)

Fig. 1 (a) Diagram of FSSW processing and (b) schematic of welding tool.

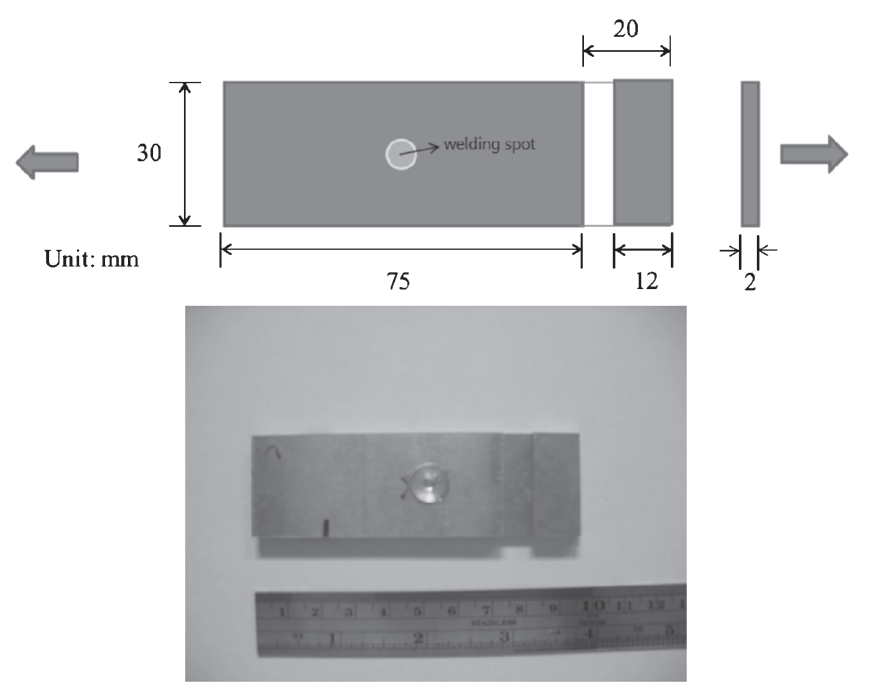

Fig. 2 Schematic of tensile-sheer specimen (top) and actual specimen (bottom).

mens was polished step-by-step to $0.06 \mu \mathrm{m}$. Then, the specimens were etched in standard Keller's solution and their microstructure was observed using optical microscopy. In addition, to determine the relationship between the microstructure and micro-hardness distribution of the FSSW specimens, the micro-hardness of the cross sections of specimens were obtained using a Vickers indenter with a 100 -g load for $10 \mathrm{~s}$. Each micro-hardness result was the average of five tests. The spacing between two indentations was wider than $0.25 \mathrm{~mm}$ to avoid strain hardening.

The fracture strength of FSSW 5083 lap-joined specimens was evaluated using a tensile-shear test with a material tester at room temperature. The tensile-shear failure load (TSFL) was recorded. Figure 2 shows a macro photograph of an FSSW lap-joined specimen before the tensile-shear test. The speed of crosshead is $1.0 \mathrm{~mm} / \mathrm{min}$. In order to ensure that the tensile direction was parallel to the pure shearing direction, two clamping pads with dimensions of $12 \mathrm{~mm}$ (length) $\times$ $30 \mathrm{~mm}$ (width) $\times 2 \mathrm{~mm}$ (thickness) rectangular sheet were stuck onto the tail of the lap-joint specimens. For the Weibull analysis, 20 lap-joined specimens were tested for each FSSW parameter.
Previous reports indicated that Weibull statistics ${ }^{24,25)}$ can be adopted to evaluate the failure probability and engineering reliability of materials. ${ }^{26-29)}$ The Weibull distribution function (eq. (1)), which describes the cumulative failure probability $F(x)$, can be used to determine the joint reliability, failure probability, and failure mechanism of FFSW lap-joints.

$$
F(x)=1-\exp \left[-\left(\frac{x-x_{0}}{\eta}\right)^{m}\right]
$$

Equation (1) has three parameters. (1) The Weibull parameter $(m)$, also called the shape parameter, represents the type of data distribution. $m<1$ represents a decreasing failure rate, $m=1$ represents a constant failure rate, and $m>1$ represents an increasing failure rate. Only the latter can be applied in industry because of the failure rate could be predict. For $m>1$, the data are concentrated on the left (smaller) side when $1<m<3$, normal distributed when $3<m<4$, and concentrated on the right (larger) side when $m>4$. In practice, the data distribution is expected to be a normal or right-side distribution; that is, the value of $m$ needs to be larger than 3. As $m$ increases, the peak of the data distribution becomes sharper. (2) The scale parameter $(\eta)$ represents the range of data distribution. When $\eta$ is small, the range of the data distribution is narrow and the peak is sharp. Therefore, it is easier to predict when failure occurs when $\eta$ is smaller. (3) The location parameter $\left(x_{0}\right)$, also called the minimum life, represents the starting point of the data distribution. In this research, $x_{0}$ is taken as the minimum TSFL. When the load is smaller than $x_{0}$, the failure probability is zero and the joining reliability is 1.0.

Three important functions derived from eq. (1) can help to analyze the reliability, as shown in Fig. 3. The reliability and failure occurrence can be determined from the curves.

$$
\begin{aligned}
f\left(x^{*}\right) & =\frac{\left.\mathrm{d} F(x)\right|_{x=x^{*}}}{\mathrm{~d} x} \\
& =\frac{m}{\eta^{m}}\left(x^{*}-x_{0}\right)^{m-1} \exp \left[-\left(\frac{x^{*}-x_{0}}{\eta}\right)^{m}\right]
\end{aligned}
$$

$f\left(x^{*}\right)$ is a probability density function. It tells the fraction of failure in a finite $x^{*}$.

$$
R\left(x^{*}\right)=1-F\left(x^{*}\right)=\exp \left[-\left(\frac{x^{*}-x_{0}}{\eta}\right)^{m}\right]
$$




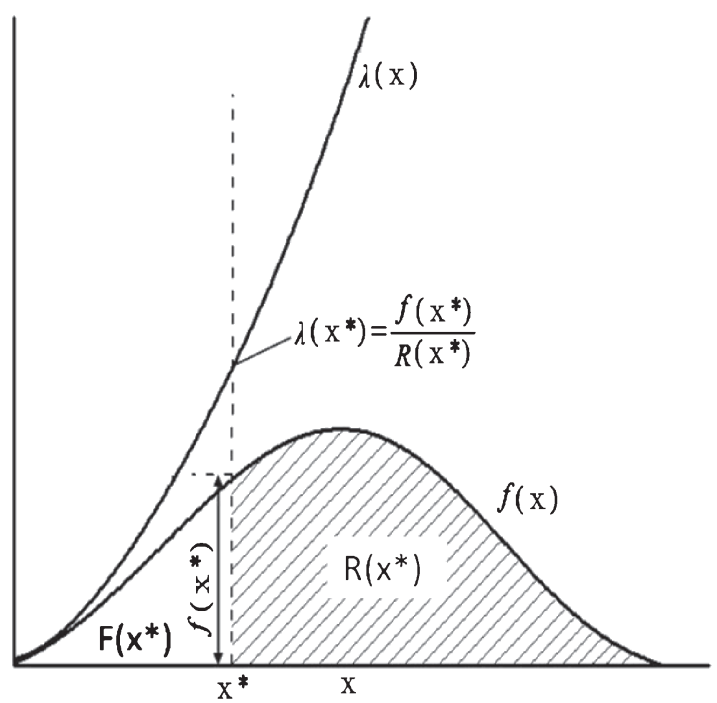

Fig. 3 Diagram of derivative functions of Weibull analysis.

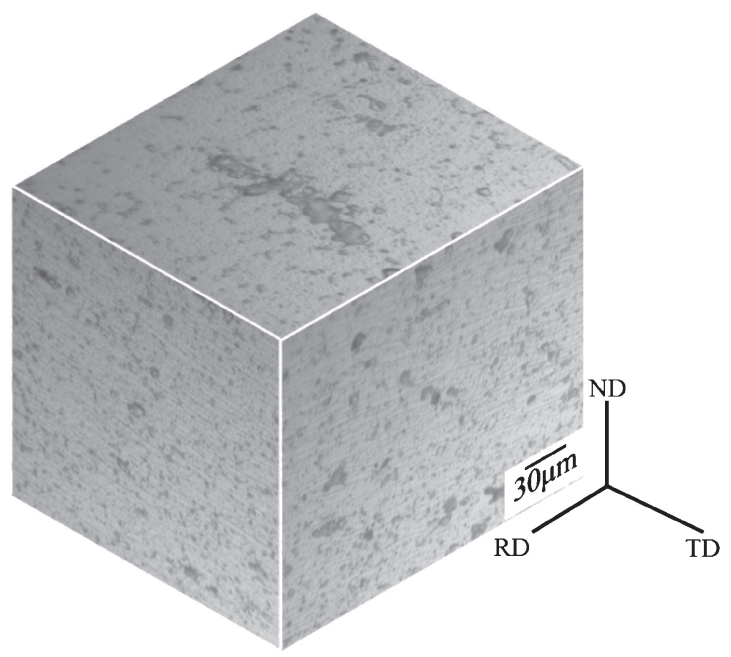

Fig. 4 Morphology of as-received $5083 \mathrm{Al}$ alloy.

(a)

(b)

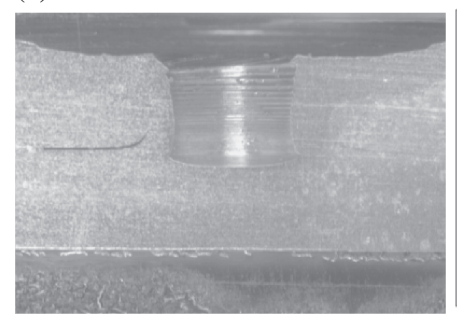

(d)

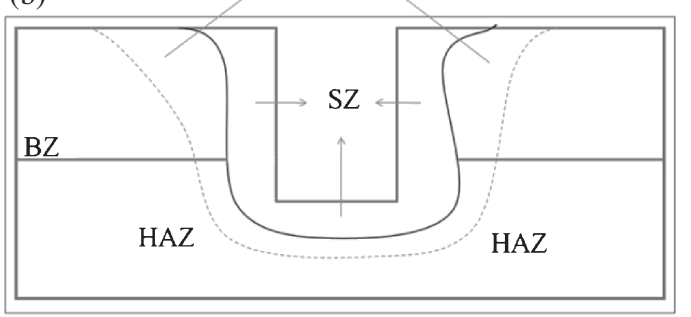

(c)

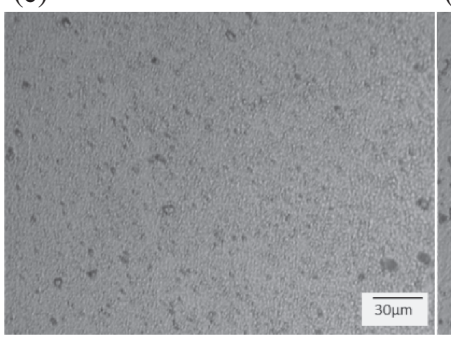

\section{(d)}

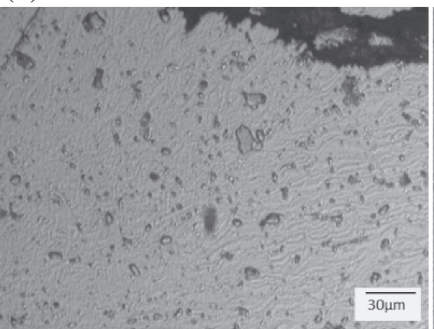

(e)

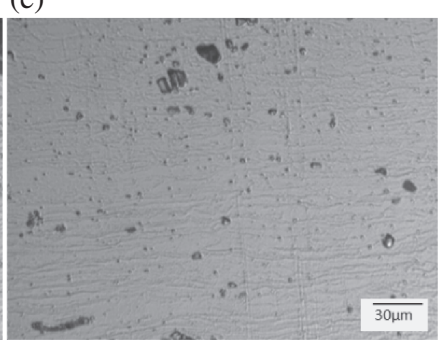

Fig. 5 Morphology of FSSW lap-joined specimen. (a) Full macrostructure of specimen, (b) schematic diagram of specimen, and microstructures of (c) SZ, (d) TMAZ, and (e) HAZ.

$R\left(x^{*}\right)$ is a reliability function that represents the survival probability of specimens from $x=0$ to $x^{*}$. For $x<x_{0}$, $R\left(x^{*}\right)=1$ (no specimen was fractured).

$$
\lambda\left(x^{*}\right)=\frac{f\left(x^{*}\right)}{R\left(x^{*}\right)}=\frac{\left.\frac{\mathrm{d} F(x)}{\mathrm{d} x}\right|_{x=x^{*}}}{R\left(x^{*}\right)}=\frac{m}{\eta^{m}}\left(x^{*}-x_{0}\right)^{m-1}
$$

$\lambda\left(x^{*}\right)$ is a failure rate function. It is the ratio of the probability density function to the reliability function.

The cumulative failure probability $F(x)$ was estimated using Benard's medium rank (eq. (5)). ${ }^{25)}$ It is a very close approximate solution of a statistical function, ${ }^{25,29)}$ where $N$ is the total number of tested samples and $i$ is the sample rank in ascending order of failure load. eq. (6) is the double natural logarithmic (ln) formula for the cumulative failure probability at each corresponding failure load $x_{i}(i=l-20$ in this study). It is used to evaluate the Weibull modulus $m$ from the slope of a least-squares fitting curve at the maximum coefficient of determination $\left(R^{2}\right)$. A high $R^{2}$, the best linear one, indicates that the experimental data can be reasonably described by the Weibull model.

$$
\begin{aligned}
F\left(x_{i}\right) & =\frac{(i-0.3)}{(N+0.4)} \\
\ln \frac{1}{1-F\left(x_{i}\right)} & =m \ln \left(x_{i}-x_{0}\right)-m \ln \eta
\end{aligned}
$$

\section{Results and Discussion}

\subsection{Microstructural evolution of FSSW}

Figure 4 shows the fiber-shaped microstructure of asextruded $5083 \mathrm{Al}$ alloy. The microstructures of various zones after FSSW are shown in Fig. 5. Figure 5(a) shows the full morphology of the specimens, and Fig. 5(b) shows the representative images of four microstructural zones: (1) SZ (stirring zone): dynamic recrystallization was induced in this zone by severe plastic deformation and frictional heat. The shape of this zone resembles a cup. Fine and equiaxed 


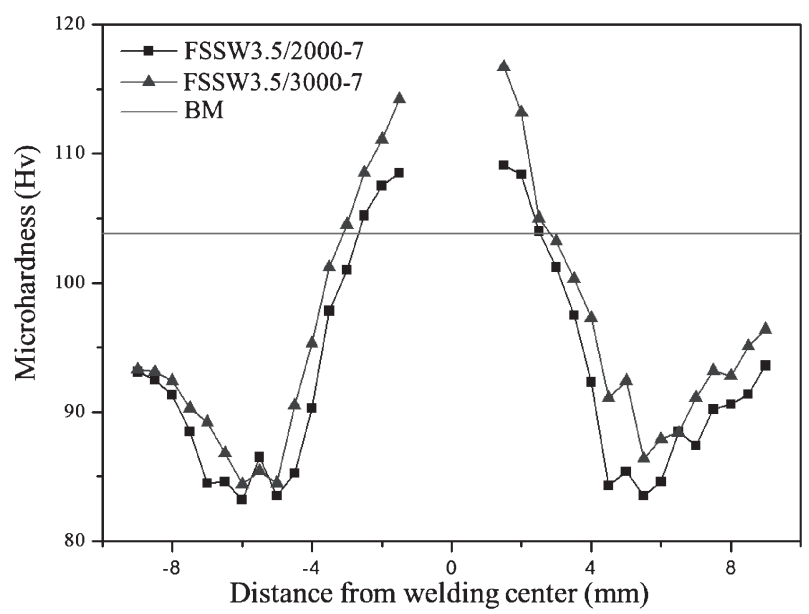

Fig. 6 Distribution of micro-hardness in lap-joined specimens.

recrystallized grains can be observed everywhere in this zone, as shown in Fig. 5(c). (2) TMAZ (thermo-mechanically affected zone): as shown in Fig. 5(d), the original fibershaped microstructure became crooked and some fine recrystallized grains grew in this zone. (3) HAZ (heataffected zone): the fiber-shaped microstructure grew only in this zone, as shown in Fig. 5(e). (4) BZ (base metal zone): the microstructure of BZ is the same as that shown in Fig. 4 due to its long distance away from the stirring zone. The ranges of these four zones change with FSSW parameters. The range of SZ is most affected; it becomes deeper with increasing plunge depth and broader with increasing welding duration. When the rotation speed was increased from 2000 to $3000 \mathrm{rpm}$, the area of SZ grew. However, a further increase to $3500 \mathrm{rpm}$ did not significantly increase the SZ area.

Figure 6 shows the distribution of micro-hardness. The measurement position was $2.1 \mathrm{~mm}$ from the top of the lapjoint specimens. FSSW3.5/2000-7 and FSSW3.5/3000-7 are used as examples. Their diagrams show the same w-shaped distribution. The hardness follows the order SZ > TMAZ > HAZ. The minimum value of hardness appeared at HAZ, and the hardness of BZ is also higher than HAZ. The SZ hardness of FSSW3.5/3000-7 was much higher and more broadly distributed than that of FSSW3.5/2000-7. It resulted from more heat and stored energy introduced into FSSW3.5/30007 by the higher rotation speed. Therefore, the recrystallized grain size was finer and range of recrystallization was larger for FSSW3.5/3000-7.

\subsection{Bonding strength and fracture modes of FSSW}

The average TSFL values and the Weibull analysis results of FSSW parameters are shown in Table 2. Figure 7 shows the variation of TSFL with FSSW parameters. The TSFL values increased obviously when the plunge depth was increased from 2.5 to $3.5 \mathrm{~mm}$. The TSFL values increased when the welding duration was increased and the plunge depth and rotation speed were fixed. There was an optimal rotation speed for increasing TSFL when the plunge depth was fixed. The optimal rotation speeds were 2500 and $3000 \mathrm{rpm}$ for plunge depths of 2.5 and $3.5 \mathrm{~mm}$, respectively. Of note, the TSFL value increased with increasing SZ area.
Table 2 Weibull analysis and average TSFL values.

(a) Plunge depth of $3.5 \mathrm{~mm}$

\begin{tabular}{|c|c|c|c|}
\hline & $2000 \mathrm{rpm}, 4 \mathrm{~s}$ & $2000 \mathrm{rpm}, 7 \mathrm{~s}$ & $2000 \mathrm{rpm}, 10 \mathrm{~s}$ \\
\hline$m$ & 1.85 & 1.91 & \\
\hline$\eta / \operatorname{kgf}$ & 18.00 & 40.22 & \\
\hline$x_{0} / \mathrm{kgf}$ & 22.63 & 25.90 & \\
\hline \multirow[t]{2}{*}{ Avg./kgf } & 40.21 & 65.10 & \\
\hline & $2500 \mathrm{rpm}, 4 \mathrm{~s}$ & $2500 \mathrm{rpm}, 7 \mathrm{~s}$ & $2500 \mathrm{rpm}, 10 \mathrm{~s}$ \\
\hline$m$ & 1.63 & 1.45 & 1.81 \\
\hline$\eta / \mathrm{kgf}$ & 27.83 & 38.32 & 46.09 \\
\hline$x_{0} / \mathrm{kgf}$ & 73.69 & 98.82 & 103.59 \\
\hline \multirow[t]{2}{*}{ Avg./kgf } & 97.92 & 132.67 & 144.30 \\
\hline & $3000 \mathrm{rpm}, 4 \mathrm{~s}$ & $3000 \mathrm{rpm}, 7 \mathrm{~s}$ & $300 \mathrm{rpm}, 10 \mathrm{~s}$ \\
\hline$m$ & 2.43 & 3.01 & 3.23 \\
\hline$\eta / \mathrm{kgf}$ & 51.42 & 96.27 & 88.51 \\
\hline$x_{0} / \mathrm{kgf}$ & 80.98 & 142.64 & 166.85 \\
\hline \multirow[t]{2}{*}{ Avg./kgf } & 126.24 & 228.42 & 252.25 \\
\hline & $3500 \mathrm{rpm}, 4 \mathrm{~s}$ & $3500 \mathrm{rpm}, 7 \mathrm{~s}$ & $3500 \mathrm{rpm}, 10 \mathrm{~s}$ \\
\hline$m$ & 2.16 & 3.11 & 3.81 \\
\hline$\eta / \mathrm{kgf}$ & 62.67 & 113.39 & 83.79 \\
\hline$x_{0} / \mathrm{kgf}$ & 65.54 & 121.32 & 142.10 \\
\hline Avg./kgf & 123.29 & 207.24 & 217.76 \\
\hline
\end{tabular}

(b) Plunge depth of $2.5 \mathrm{~mm}$

\begin{tabular}{cccc}
\hline & $2000 \mathrm{rpm}, 10 \mathrm{~s}$ & $2500 \mathrm{rpm}, 10 \mathrm{~s}$ & $3000 \mathrm{rpm}, 10 \mathrm{~s}$ \\
\hline$m$ & 2.75 & 2.64 & 2.17 \\
$\eta / \mathrm{kgf}$ & 42.50 & 59.95 & 41.99 \\
$x_{0} / \mathrm{kgf}$ & 83.62 & 94.81 & 79.39 \\
Avg./kgf & 120.80 & 147.89 & 116.17 \\
\hline
\end{tabular}

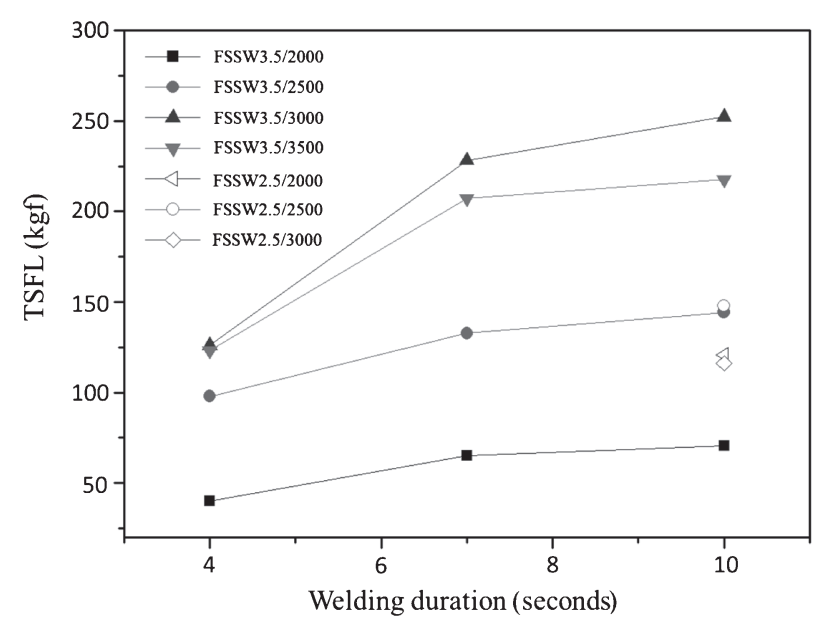

Fig. 7 Average TSFL values for various specimens.

From the tensile-shear fracture specimens for all FSSW parameters, two modes of fracture were identified. (1) Tearing mode: a major crack originated at the interface of the two original stacking sheets, and propagated toward the welding hole. When the fractural route penetrated SZ, the specimen broke. (2) Cup pull-out mode: a major crack originated at the same position as that for tearing mode, but it did not propagate toward the welding hole. The crack proceeded along the edge of SZ, creating a fracture that 
(a)

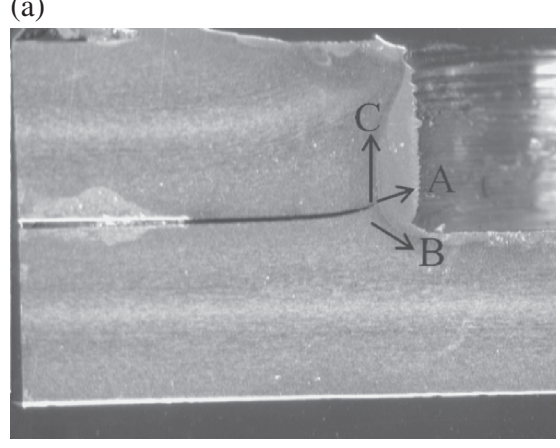

(b)

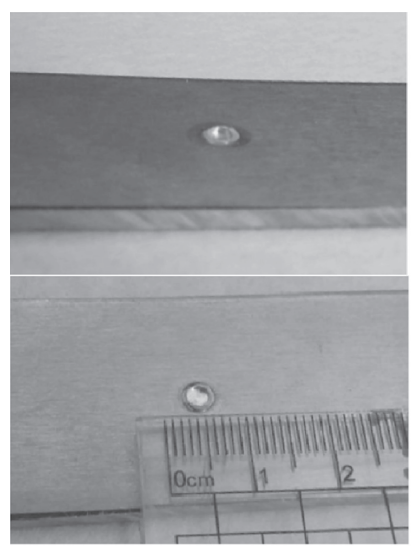

(c)

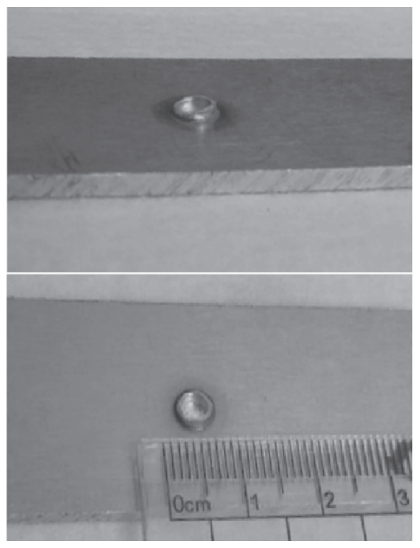

(d)

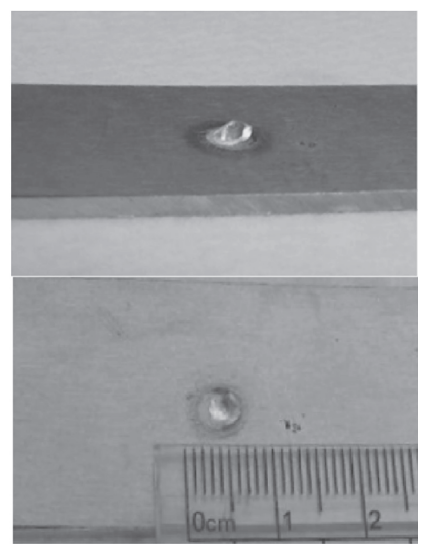

Fig. 8 (a) Schematic of crack propagation routes and final fractural appearances of specimens with (b) tearing mode, (c) cup pull-out mode, (d) mixed mode.

Table 3 Major fracture modes for various specimens.

\begin{tabular}{cccc}
\hline \multicolumn{4}{c}{ Plunge depth of 3.5 mm } \\
\hline Sample & FSSW3.5/2000-4 & FSSW3.5/2000-7 & FSSW3.5/2000-10 \\
Fracture mode & Tearing mode & Tearing mode & \\
Sample & FSSW3.5/2500-4 & FSSW3.5/2500-7 & FSSW3.5/2500-10 \\
Fracture mode & Tearing mode & Tearing mode & Tearing mode \\
Sample & FSSW3.5/3000-4 & FSSW3.5/3000-7 & FSSW3.5/3000-10 \\
Fracture mode & Mixed & Cup pull-out mode & Cup pull-out mode \\
Sample & FSSW3.5/3500-4 & FSSW3.5/3500-7 & FSSW3.5/3500-10 \\
Fracture mode & Mixed & Cup pull-out mode & Cup pull-out mode \\
\hline \multicolumn{4}{c}{ Plunge depth of 2.5 mm } \\
\hline Sample & FSSW2.5/2000-10 & FSSW2.5/2500-10 & FSSW2.5/3000-10 \\
Fracture mode & Mixed & Cup pull-out mode & Mixed \\
\hline
\end{tabular}

resembles a cup. Figure 8(a) shows the crack propagation routes of these two fracture modes (arrow A indicates the route of the tearing mode and arrows $\mathrm{B}$ and $\mathrm{C}$ indicate the route of the cup pull-out mode). Figure 8(b)-(d) show the final fracture appearances for tearing mode (FSSW3.5/20007), cup pull-out mode, and mixed mode (both tearing mode and cup pull-out mode, FSSW3.5/3000-4), respectively. Table 3 shows the statistical results of the fracture mode for various specimens. If the major fracture mode was tearing mode, the TSFL is low, according to the microstructural observation, the SZ area was small due to the low degree of recrystallization, and thus the crack penetrated SZ and TSFL decreased. Contrarily, the cup pull-out mode resulted in a higher TSFL due to area of SZ was larger than that of tearing mode specimens.

\subsection{Reliability of fracture mode measured using Weibull analysis}

The Weibull analysis results for various specimens are shown in Fig. 9 and Table 2. Only the results for FSSW3.5/3000-7, FSSW3.5/3000-10, FSSW3.5/3500-7, and FSSW3.5/3500-10 (four FSSW parameters) are normal distributed, since their $m$ values were larger than 3 . Weibull parameter $(m)$ increasing with increasing plunge depth and welding duration and $\eta$ increased with increasing rotation speed and welding duration. Even was at lower rotation speeds that represented data concentrated, but its $m$ was still small so the reliability was also bad. The tendency of $x_{0}$ is similar to that of average TSFL. It was much easy to judge whether the FSSW parameter could apply or not.

The data distribution and reliability can be determined from $R(x)$ and $\lambda(x)$ in Fig. 9. A curve that is toward the right side (larger $x_{0}$ ) and steep (larger $m$ and smaller $\eta$ ) represents high bonding strength and it is easier to predict how high the TSFL make specimens fracture. Based on the Weibull analysis, the optimal FSSW parameters can be selected for a particular application.

In Table 2 and Table 3, the major fracture mode of specimens with those four FSSW parameters whose $m$ is larger than 3 is the cup pull-out mode. When the fracture mode became the tearing mode, $m, \eta$, and $x_{0}$ became smaller. The TSFL values were concentrated more toward the left side, the data distribution became narrow, and the bonding 


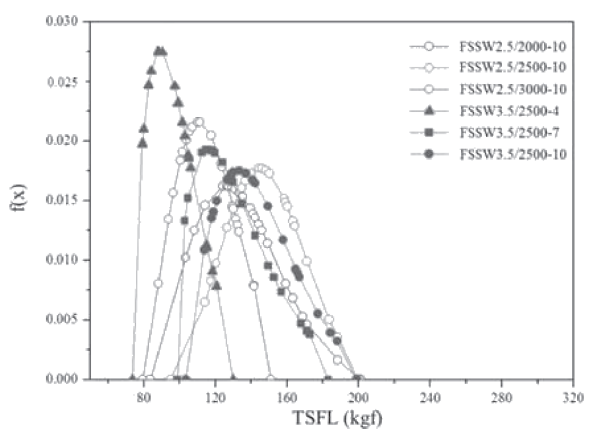

(a)

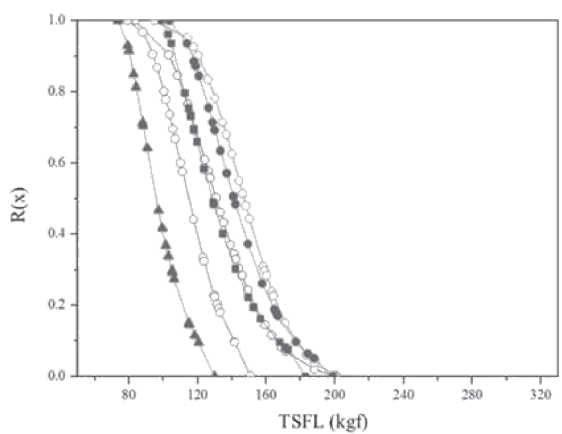

(c)

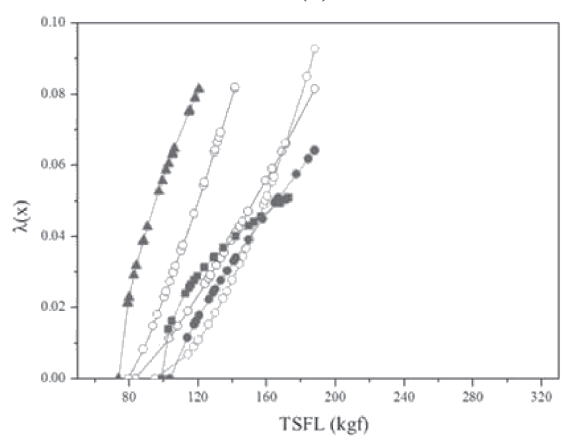

(e)

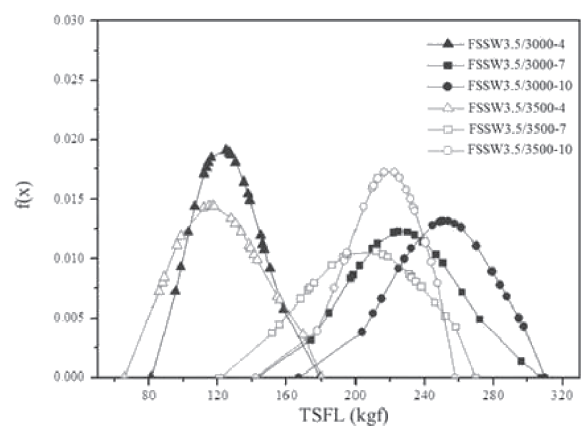

(b)

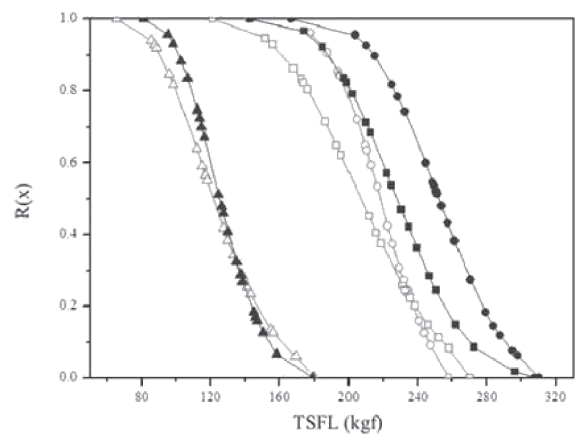

(d)

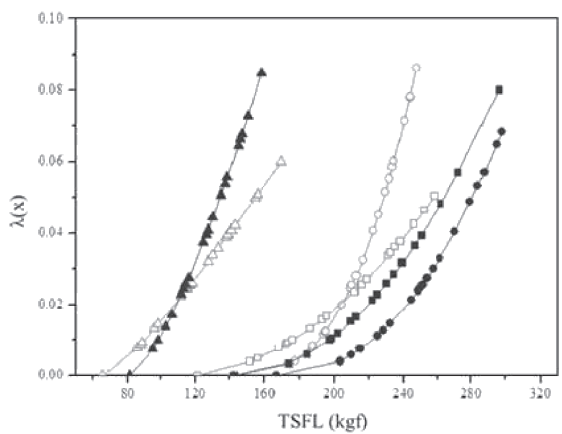

(f)

Fig. 9 Results of Weibull analysis. $f(x), R(x)$, and $\lambda(x)$ for plunge depths of (a), (c), (e) $2.5 \mathrm{~mm}$ and (b), (d), (f) $3.5 \mathrm{~mm}$.

strength decreased when the major fracture mode was tearing mode.

\section{Conclusions}

(1) TSFL increased when the range of SZ increased. And as plunge depth changed, the most optimal rotation speed for obtaining higher TSFL changed.

(2) The two fracture modes of TSFL were the cup pull-out mode and the tearing mode. When the range of SZ was deeper and broader, the cup pull-out mode was more likely to occur.

(3) The reliability and bonding strength of the cup pull-out specimens were better than those of the tearing mode parameters.

\section{Acknowledgements}

The authors are grateful to the Instrument Center of National Cheng Kung University and the National Science Council of Taiwan (grant NSC 103-2221-E-006-066) for their financial support.

\section{REFERENCES}

1) K. Chandra and V. Kain: Eng. Failure Anal. 34 (2013) 387-396.

2) F. Hayat: Mater. Sci. Eng. A 556 (2013) 834-843.

3) S. Lathabai, M. J. Painter, G. M. D. Cantin and V. K. Tyagi: Scr. Mater. 55 (2006) 899-902.

4) H. Fujii, M. Maeda and K. Nogi: Mater. Sci. Eng. A 354 (2003) 298305.

5) D. A. Wang and S. C. Lee: J. Mater. Proc. Tech. 186 (2007) 291-297.

6) M. Ericsson, L. Z. Jin and R. Sandstrom: Int. J. Fatigue 29 (2007) 5768.

7) F. J. Humpheys and M. Hathrly: Recrystallization and Related Annealing Phenomena, (Pergamon, Oxford, UK, 1996).

8) K. V. Jata and S. L. Semiatin: Scr. Mater. 43 (2000) 743-749.

9) L. Faratmi and G. Buffa: Int. J. Mach. Tools Manuf. 45 (2005) 11881194.

10) C. G. Phodes, M. W. Mahoney, M. H. Bingel and M. Cakabrese: Scr. Mater. 48 (2003) 1451-1455.

11) J. Q. Su, T. W. Nelon and C. J. Sterling: Mater. Sci. Eng. A 305 (2004) 277-285.

12) Y. S. Sato, M. Urata, H. Kokawa and K. Ikeda: Mater. Sci. Eng. A 354 (2003) 298-305.

13) A. Gerlich, P. Su and T. H. North: J. Mater. Sci. 40 (2005) 6473-6481.

14) D. Mitlin, V. Rodmilovic, T. Pan, J. Chen, Z. Feng and M. L. Santella: Mater. Sci. Eng. A 441 (2006) 79-96.

15) S. Bozzi, A. L. Helbert-Etter, T. Baudin, V. Klosek, J. G. Kerbigust and 
B. Criqui: J. Mater. Proc. Tech. 210 (2012) 1429-1435.

16) P. D. T. O'Connor: Practical Reliability Engineering $3 r d$ Ed., (John Wiley and Sons, 1991) Chap. 1-6.

17) K. C. Sons: Reliability in Engineering Design, (John Wiley and Sons, 1977) Chap. 1-6.

18) A. D. S. Cater: Mechanical Reliability 2nd ed., (John Wiley and Sons, 1986) Chap. 2 and 11.

19) B. Faucher and W. R. Tyson: J. Mater. Sci. Lett. 7 (1988) 1199-1203.

20) S. H. Dai and M. O. Wang: Reliability Analysis in Engineering Application, (Van Nostrand Reinhold, 1992) pp. 353-359.

21) X. D. Li and L. Edwards: Eng. Fract. Mech. 20 (1996) 35-48.

22) C. W. Yang, F. Y. Hung, T. S. Lui, L. H. Chen and J. Y. Juo: Mater.
Trans. 50 (2009) 145-151.

23) P. C. Chakraborti, A. Kundu and B. K. Dutta: Mater. Sci. Eng. A 594 (2014) 89-97.

24) W. Weibull: J. Appl. Mech. 18 (1951) 293-297.

25) R. B. Abernethy: The New Weibull Handbook: Reliability and Statistical Analysis for Predicting Life, Safety, Survivability, Risk, Cost and Warranty Claims, 4th ed., (North Palm Beach, FL, 2000).

26) Y. Y. Zhao, E. Ma and J. Xu: Scr. Mater. 58 (2008) 496-499.

27) C. W. Yang and T. S. Lui: J. Eur. Ceram. Soc. 28 (2008) 2151-2159.

28) S. S. Scherrer, I. L. Denry, H. W. Anselm Wiskott and U. C. Belser: Dent. Mater. 17 (2001) 367-371

29) B. Faucher and W. R. Tyson: J. Mater. Sci. Lett. 7 (1988) 1199-1203. 